\title{
INTRATEMPORAL FACIAL NERVE TRAUMA- A STUDY OF 40 CASES
}

\author{
Mummoolayil Babu Nishant ${ }^{1}$
}

${ }_{1}^{1}$ Assistant Professor, Department of ENT, Sree Gokulam Medical College and Research Foundation, Trivandrum, Kerala. ABSTRACT

\section{BACKGROUND}

Acute facial paralysis can result from various causes, among which intratemporal facial palsy is most common. Of all the cranial nerves, the facial nerve is most susceptible to injury due to its long course within the skull. Diagnosis of facial nerve disorders can usually be made by a good clinical history, clinical examination supplemented by radiological investigations. Electrophysiological tests are important in prognosis and can give an idea about the optimal time for surgery. Many cases of trauma recover with conservative treatment including steroids and physiotherapy. Surgery in these cases is still controversial. The present study was undertaken to understand the different treatment modalities, which can be applied for various cases of traumatic facial palsy. Objective- A study of traumatic intratemporal facial nerve paralysis, treatment options and their outcomes.

\section{MATERIALS AND METHODS}

This case series consists of 40 patients who presented to our hospital with traumatic facial palsy. Patients were examined and graded using House and Brackmann grading system. After necessary investigations, patients were then treated either conservatively or by surgical decompression. Follow-up was carried out intermittently until 6 months.

\section{RESULTS}

Out of 40 patients of traumatic facial nerve palsy studied, 28 were due to accidental trauma to the head and 12 due to surgical trauma. 20 out of 28 patients with temporal bone trauma had good recovery, 4 had moderate recovery and 4 poor recovery. Among the surgical trauma group, all 12 patients showed complete recovery.

\section{CONCLUSION}

Early initiation of treatment is important for a favourable recovery of facial nerve function after trauma. Majority of the cases can be treated conservatively. Surgical treatment is indicated in suspected bony impingement of the nerve. Surgical trauma, if identified and managed promptly usually results in good recovery. Transverse fractures are usually associated with poor prognosis.

\section{KEYWORDS}

Trauma, Facial Paralysis, Longitudinal Fracture, Hearing Loss.

HOW TO CITE THIS ARTICLE: Nishant MB. Intratemporal facial nerve trauma- a study of 40 cases. J. Evolution Med. Dent. Sci. 2018;7(12):1465-1467, DOI: $10.14260 /$ jemds/2018/332

\section{BACKGROUND}

Of all the cranial nerves, the facial nerve is most susceptible to injury. The nerve travels a complex course through the temporal bone starting from the internal acoustic meatus to the stylomastoid foramen. Among its functions are the vital control of facial expression, taste to the anterior two-third of the tongue and salivary and lacrimal gland secretion. Patients who suffer from facial paralysis experience not only functional consequences, but also the psychological impact of a change in self-image and impaired communication ability. Management of facial nerve dysfunction is individualised and may include observation, administration of pharmacological agents, surgical interventions, physical therapy and psychological counseling. ${ }^{1}$

Traumatic facial palsy is not an infrequent complication of skull fracture. $90 \%$ of the fractures are longitudinal and the remaining $10 \%$ are transverse. ${ }^{2}$

'Financial or Other Competing Interest': None.

Submission 10-03-2017, Peer Review 03-03-2018,

Acceptance 10-03-2018, Published 19-03-2018.

Corresponding Author:

Dr. Mummoolayil Babu Nishant,

Geethanjali, EVRA 68, TC 16/515-1,

Near Jagathy School, Thyacud P. O.,

Thiruvananthapuram-695014, Kerala.

E-mail: nishant9000@gmail.com

DOI: $10.14260 /$ jemds $/ 2018 / 332$
The facial nerve usually escapes longitudinal fractures, but is injured in transverse fractures of the petrous temporal bone. Facial paralysis occurs in approximately $20 \%$ of longitudinal and $50 \%$ of transverse fractures.

Because incidence of longitudinal fractures is greater than that of transverse fractures, facial paralysis secondary to longitudinal fractures is more frequently encountered. In longitudinal fracture, the nerve is most frequently injured in the perigeniculate region. In transverse fractures, it is usually the labyrinthine segment and geniculate segment. ${ }^{3}$ Hemanth Chopra et al conducted a study of 500 cases of head injury between Jan. 1991 and March 2001. ${ }^{4}$ In that study, 48 cases (9.6\%) had facial paralysis 13 (27.1\%) had immediate onset and 21 (43.7\%) had delayed onset, while in 14 cases (29\%) the patient was unconscious. 19 patients (51.3\%) had longitudinal fracture, 7 (18.9\%) transverse and 11 (29.7\%) comminuted. Noah Massa (2003) 2,5 studied 67 cases of longitudinal fractures and found that $76 \%$ had bony impingement or intraneural haematoma, $15 \%$ showed transaction and the rest no pathology except neural oedema. In contrast of 11 transverse fractures received, 92\% were transected and $8 \%$ had bony impingement.

Surgical injury to the facial nerve following operation on the ear calls for an immediate exploration, unless the surgeon has identified the nerve during surgery and is sure that the nerve is intact in which case the paralysis is probably caused 
by oedema. If paralysis is immediate in onset, surgical exploration of the nerve is advised. The indications for facial nerve exploration and decompression are similar to that for Bell's palsy. Delayed onset paralysis is usually managed conservatively. J Douglas Green, Clough Shelton and Derald E Brackmann (1994) reviewed 22 patients with iatrogenic facial palsy. ${ }^{5}$ Although, the most common procedure being performed during the surgery was mastoidectomy (55\%), patients had injury during tympanoplasty $(14 \%)$ or during removal of exostoses (14\%). The most common area of injury was the lower tympanic segment (55\%) and the descending mastoid segments (32\%). Only 2 patients in this study had an abnormal course of the facial nerve. A lack of familiarity with the temporal bone anatomy appears to have contributed to the facial nerve injury in majority of these patients. The injury was not recognised in as much as $79 \%$ of the patients.

\section{MATERIALS AND METHODS}

This case series consists of 40 patients with intratemporal facial nerve trauma seen at a tertiary care medical college in South India between 2010 and 2016. All patients were examined and graded using House and Brackmann grading system. ${ }^{6}$ These patients then underwent audiological, topodiagnostic and radiological investigations wherever required. Out of 40 patients 34 were managed conservatively, while 4 patients underwent transmastoid decompression and 2 patients had middle cranial fossa decompression. Follow-up examination was done at periods of 1 month, 3 months and 6 months using the House and Brackmann system. The facial nerve outcome at 6 months was used to stage into good (Grade 1 and 3), moderate (Grade 3 and 4) or poor recovery (Grade 5 and 6).

\section{RESULTS}

Out of the 40 patients of intratemporal facial nerve palsy studied, 28 were due to external trauma to the temporal bone and 12 due to surgical trauma. Out of 28 patients, 16 (57\%) had immediate onset facial palsy and the remaining 12 (43\%) had delayed onset palsy. In the 12 patients with iatrogenic injury, the paralysis was noted in the immediate postoperative period.

All patients with external injury were advised an HRCT scan of the temporal bone. Out of these, 20 patients had evidence of fracture, 12 were cases of longitudinal fracture $(60 \%), 6$ patients had transverse fracture $(30 \%)$ and 2 had a combination of longitudinal and transverse fracture of temporal bone (10\%). 8 patients had no radiological evidence of any fracture.

All patients underwent Pure Tone Audiometry (PTA) and Stapedial reflex testing. Hearing loss was present in 14 out of 28 patients, out of which 12 patients had conductive hearing loss. 2 patients with comminuted fracture had sensorineural hearing loss. Stapedial reflex was abnormal in 14 out of 28 patients. Schirmer's test was abnormal in 20 out of 28 . Taste loss was present in 14 out of 28 patients. Among the 12 patients with iatrogenic palsy, none had hearing loss, but taste loss was present in 4 patients.

All patients with delayed onset facial palsy were treated conservatively with anti-inflammatory drugs and steroids. Out of 16 patients with immediate onset palsy, 4 had definite fracture line transecting the facial nerve with bony impingement as seen on HRCT. All these patients underwent transmastoid decompression of the nerve and end-to-end anastomosis. 2 patients with comminuted fracture underwent middle cranial fossa decompression. The remaining 10 patients were treated conservatively with steroids and physiotherapy. The 12 patients with delayed traumatic palsy were also treated conservatively.

Among the 12 patients of post-operative facial palsy, 10 had undergone mastoidectomy and 2 patients underwent stapedectomy. All patients were treated conservatively and recovered fully.

\section{Recovery in Head Injury}

\begin{tabular}{|c|c|}
\hline Total No. of Cases & 28 \\
\hline Total No. of Good Function & $20(71.4 \%)$ \\
\hline Total No. of Moderate Function & $4(14.3 \%)$ \\
\hline Total No. of Poor Function & $4(14.3 \%)$ \\
\hline Table 1. Facial Nerve Outcome after Head Injury \\
\hline
\end{tabular}

Recovery in Surgical Trauma

\begin{tabular}{|c|c|}
\hline Total No. of Cases & 12 \\
\hline Total No. of Good Function & 12 \\
\hline Total No. of Moderate Function & 0 \\
\hline Total No. of Poor Function & 0 \\
\hline Table 2. Facial Nerve Outcome after Surgical Trauma \\
\hline
\end{tabular}

\section{DISCUSSION}

\section{Head Injury}

The present study consisted of 40 patients of intratemporal facial nerve trauma, out of which 28 cases were due to head injury and 12 cases were due to iatrogenic injury. Among the head injury patients all the cases were due to road traffic accidents, which is still one of the most common causes of head injury. 16 out of $28(57 \%)$ cases had immediate onset facial palsy and the remaining had late onset facial palsy. 24 out of 28 patients gave history of ear bleed and examination revealed blood clots within the ear canal. Two patients gave no history of ear bleed, but had a haemotympanum.

All patients with traumatic facial palsy were advised a CT scan of the temporal bone. Out of these 20 patients with evidence of fracture, 12 were cases of longitudinal fracture (60\%), 6 patients had transverse fracture (30\%) and 2 had a combination of longitudinal and transverse fractures of temporal bone (10\%). 2 had definite fracture line transecting the facial nerve with bony impingement as seen on HRCT. Hemanth Chopra et al in their study of 48 cases of facial paralysis found that the incidence of longitudinal fracture was $51 \%$ and transverse fracture was $19 \%{ }^{4}$ This is comparable to what was obtained in our study. Ulug and Ulubil in their study of 11 traumatic facial palsies found that 7 (63\%) were longitudinal and $4(37 \%)$ were mixed type. ${ }^{7}$ No transverse fractures were seen. The percentage of comminuted fracture was $30 \%$, while in our study it was lower at $10 \%$.

\begin{tabular}{|c|c|c|c|}
\hline $\begin{array}{c}\text { Type of } \\
\text { Fracture }\end{array}$ & $\begin{array}{c}\text { Present } \\
\text { Study }\end{array}$ & $\begin{array}{c}\text { Hemanth } \\
\text { Chopra }^{4}\end{array}$ & $\begin{array}{c}\text { Ulug and } \\
\text { Ulubil7 }^{7}\end{array}$ \\
\hline Longitudinal & $12(60 \%)$ & $19(52 \%)$ & $7(63 \%)$ \\
\hline Transverse & $6(30 \%)$ & $7(19 \%)$ & 0 \\
\hline Comminuted & $2(10 \%)$ & $11(30 \%)$ & $4(37 \%)$ \\
\hline Table 3. Table comparing the Types of Bony Injury in \\
Traumatic Facial Palsy \\
\hline \multicolumn{4}{|c|}{} \\
\hline
\end{tabular}


Hearing loss was seen in 14 out of 28 patients. 12 out of those had conductive hearing loss (CHL), while 2 patients with comminuted fracture had sensorineural hearing loss (SNHL). The patients with SNHL had poor recovery of their facial nerve function and hearing. Out of the remaining 12 with CHL, 8 had complete recovery, 2 partial recovery and the remaining 2 patients had poor recovery. In the study by Ozgirgin and Ozluoglu on 18 patients with temporal bone fracture, 16 had longitudinal fracture and 2 had transverse fracture. ${ }^{8}$ Both patients with transverse fracture had severe SNHL and had poor recovery of his facial nerve function. The presence of hearing loss was found to be associated with poor recovery of facial nerve function. Schirmer's test was negative in 20 out of 28 patients. 16 out this 20 had complete recovery and 4 had poor recovery. Stapedial reflex was abnormal in 10 out of 28 patients. Out of this 2 had partial recovery, 2 patients had poor recovery and the remaining complete recovery. Taste loss was present in 14 out of 28 patients. Schirmer's test and stapedial reflex did not correlate with the presence of documented fracture seen on CT scan of the temporal bone. They were also not consistent with recovery from paralysis.

All patients with transecting fracture lines were treated surgically with transmastoid decompression of the nerve and end-to-end anastomosis. 2 of these patients had poor recovery and another 2 had partial recovery. Hence, only 2 in $6(33 \%)$ patients with transverse fracture had complete recovery of facial function. The 2 patients with comminuted fracture had intracranial bleed as complication and had to be treated with middle cranial fossa decompression together with evacuation by the neurosurgeon. These 2 patients also had poor recovery of his facial nerve function. All remaining 22 patients including those with delayed onset facial palsy were treated conservatively with anti-inflammatory drugs and steroids. These patients showed good recovery of their facial function. In the study of 11 patients treated by Ulug and Ulubil $^{9}(82 \%)$ had good recovery of function, while $2(28 \%)$ patients had moderate recovery of function. ${ }^{7}$ Ozgirgin and Ozluoglu in their study of 18 cases of temporal bone fracture, $16(89 \%)$ had good recovery and $2(11 \%)$ had moderate recovery. ${ }^{8}$ In comparison our study showed good recovery in $72 \%$, moderate in $14 \%$ and poor recovery in $14 \%$.

\begin{tabular}{|c|c|c|c|}
\hline $\begin{array}{c}\text { Facial } \\
\text { Function }\end{array}$ & $\begin{array}{c}\text { Present } \\
\text { Study }\end{array}$ & $\begin{array}{c}\text { Ulug and } \\
\text { Ulubil }\end{array}$ & $\begin{array}{c}\text { Ozgirgin and } \\
\text { Ozluoglu }\end{array}$ \\
\hline $\begin{array}{c}\text { Good } \\
\text { (HB 1 and } 2)\end{array}$ & $20(72 \%)$ & $9(82 \%)$ & $16(89 \%)$ \\
\hline $\begin{array}{c}\text { Moderate } \\
\text { (HB 3 and 4) }\end{array}$ & $4(14 \%)$ & $2(28 \%)$ & $2(11 \%)$ \\
\hline Poor (HB 5 and 6) & $4(14 \%)$ & & \\
\hline \multicolumn{4}{|c|}{ Table 4. Facial Function after Medical and/or Surgical } \\
Treatment
\end{tabular}

\section{Surgical Trauma}

In the present study, 12 out of 40 cases (30\%) were due to surgically induced paralysis. Out of the 12 patients, 10 (83\%) had undergone radical mastoidectomy and 2 had undergone stapedectomy. Douglas JG, Clough S and Derald EB in their study of 22 patients of iatrogenic facial palsy found that the most common surgery leading to facial nerve injury was mastoidectomy accounting for $55 \%$ in their study. ${ }^{9}$ The second most common surgery was removal of exostosis.
Exostosis is not commonly seen in our clinical practice and hence the surgery is less commonly done.

The patients who underwent stapedectomy developed facial paralysis intraoperatively, but recovered within 4 - 5 hours after surgery. This paralysis was possible as a result of the local anaesthesia. In the remaining cases, paralysis could be due to the heat generated during drilling. In all cases, the facial canal was identified intraoperatively. It was decided to treat these patients conservatively with steroids and recovery was seen within 3 weeks.

\section{CONCLUSION}

Facial nerve is the seventh cranial nerve and is the nerve of facial expression. Due to the long and complicated course of the nerve through the temporal bone, it is prone to injury from various causes. Trauma is the second most common cause of intratemporal facial palsy after Bell's palsy. The recent incidence of accidental injury to facial nerve has significantly reduced due to better safety measures employed to reduce the morbidity and mortality due to road traffic accidents. Likewise, surgical injury to the facial nerve has also reduced with the routine use of microscopes and better training of otolaryngologists. Even so, cases which present to the otolaryngologist still present a management difficulty. Diagnosis requires clinical examination supplemented by radiological investigations. Electrophysiological tests are important in prognosis and can give an idea about the optimal time for surgery. The majority of cases of trauma recover with conservative treatment including steroids and physiotherapy. Surgery is necessary when there is a documented fracture line transecting the nerve canal. Transverse fractures are usually associated with poor recovery of facial function.

\section{REFERENCES}

[1] Ravi NS, Bruce JG. Surgery of the facial nerve. In: Micheal EG, Aina JG. Surgery of the ear. $5^{\text {th }}$ edn. Canada: BC Decker, 2003.

[2] Schaitkin BM, May M. Disorders of facial nerve. In: Kerr AG, Bueth JB. Scott-Brown's otolaryngology. $6^{\text {th }}$ edn. London: Butterworth-Heinmann, 1997.

[3] Newton JC. Management of traumatic injury to the facial nerve. Otolaryngol Clin North Am 1991;24(1):215-27.

[4] Hemanth C, Khurana AS, Munjal M, et al. Facial nerve paralysis in head injury. Indian Journal of Otology 2002;8:86-9.

[5] Douglas GJ, Clough S, Derald EB. Iatrogenic facial nerve injury during ontological surgery. Laryngoscope 1994;104(8 Pt 1):922-6.

[6] May M, Schaitkin BM. The facial nerve. $2^{\text {nd }}$ edn. New York: Thieme, 2000.

[7] Ulug T, Ulubil AS. Management of facial paralysis in temporal bone fractures: a prospective study analyzing 11 operated fractures. Am J Otolaryngol 2005;26(4):230-8.

[8] Ozgirgin ON, Ozluoglu L. Facial nerve injuries revisited. The Mediterranean Journal of Otology 2006;3:127-32.

[9] Philip AW, John SR. Facial paralysis. In: Snow JB, Ballenger JJ. Otorhinolaryngology and head and neck surgery. 16th edn. Spain: BC Decker, 2004. 